\title{
Influences of persistent psychosocial stress in the real world on mental and physiological states in female college students
}

Sokichi Sakuragi

*Correspondence: ssakurag@auecc.aichi-edu.ac.jp

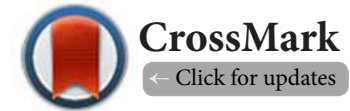

Department of School Health Sciences, Aichi University of Education, Hirosawa 1, Igaya-cho, Kariya 448-8542, Japan.

\begin{abstract}
Teaching practice is essential for students who want to be a teacher, and many students feel stress during the practice period, but precise effects of the persistent stress on mental and physiological state are not completely understood. To clarify the influence of persistent psychosocial stress, Cornell medical index (CMI) score, state-trait anxiety inventory (STAI) score, and systolic and diastolic blood pressure were measured during the teaching practice period and control period, in female college students who were having 4 weeks of teaching practice. Autonomic and mood responses to physical (orthostatic challenge) and psychological (Stroop color-word conflict test) stimuli were also evaluated during both periods, using a profile of mood states and a visual analogue scale (VAS) for mood estimation, and a spectral analysis of heart rate variability (HRV) for autonomic nervous activity estimation. Subjective symptoms assessed by CMI, state and trait anxiety, and diastolic blood pressure were significantly higher during the practice period, and the effect size of trait anxiety difference was the largest. Repeated measures analysis of variance revealed significant interaction in T-A, D, F, C score in POMS, that is, pre-stimulus basal level of these negative mood scales were higher and reduced more after the acute stimulus during the practice period compared to those during the control period. There was some tendency that unstable recovery in $\mathrm{HF}$ amplitude of $\mathrm{HRV}$ after the psychological stimulus during the practice period, compared to abrupt and stable recovery during the control period, though the statistical value did not reach significant level. These results suggest that persistent psychosocial stress in the real world would make person more anxious and complain more subjective symptoms, along with higher basal diastolic blood pressure and some what unstable autonomic recovery after acute psychological stimulus during the practice period. Periodical survey of anxiety, especially trait anxiety, and precise diastolic BP monitoring on a regular basis can become useful tools to detect persistently stressed state.
\end{abstract}

Keywords: Persistent psychosocial stress, teaching practice, heart rate variability, profile of mood states, state-trait anxiety inventory

\section{Introduction}

Recently, many people are exposed to various psychosocial stressors, and influences of stress, stress related diseases or disorders have been vigorously investigated [1-4]. Mental stress have some effects on mood, mental state, autonomic nervous system, endocrine system and immune system [5-7]. Stress is believed to be beneficial to growth and development when its duration is brief and its intensity is adequate, whereas stress would be harmful when its duration is long and/or its intensity is excessive $[\mathbf{8 , 9}]$. However, it is still difficult to discriminate good stress from bad one. Generally, long lasting excessive stressors are bad for health, and it is important to know the stressed state before falling ill. Laboratory induced acute stress usually induces sympathetic activation with parasympathetic withdrawal and hypothalamo-pituitary-adrenal axis activation $[\mathbf{7 , 1 0}]$, however, the stress responses would be different between individuals depending on their personality or the level of stressed state $[\mathbf{7 , 1 1}]$. Acute stress responses 
were examined in subjects under persistent psychosocial stress in the real world in some previous articles, but the results were not enough to predict pre-disease stressed state [12-14].

Teaching practice is an essential practice for students who want to be a teacher, and the practice is very different from general university classes and usually high demanding. Therefore, many students usually feel stress during the teaching practice period and some feel stress even after the period, but the precise characteristic of stress response in mental and physiological system when stressor continues for weeks are not determined. That is, mental and physiological state including reactivity to acute stress in persons who have been under persistent psychosocial stress in the real world is not precisely understood. As far as I know, precise pathophysiological process of stress related diseases or disorders under persistently stressed condition is still complex and not completely understood. To clarify the influence of persistent psychosocial stress in the real world on mental state and physiological state, we studied mental state and autonomic nervous activity of female college students during teaching practice period, and compared them with those during the control period (after the practice period), along with the response characteristics to physical (orthostatic challenge) and psychological (Stroop color-word conflict test) stimuli, in female college students who were having 4 weeks of practice teaching in elementary schools. Mental states were evaluated by Cornell Medical Index (CMI) $[15,16]$, State Trait Anxiety Inventory (STAI) [17], Visual analogue scale (VAS) [18-20], and profile of mood states (POMS) [21], and autonomic nervous activity was evaluated by a spectral analysis of heart rate variability (HRV), which is a powerful tool for evaluating autonomic nervous function non-invasively [22-28], and systolic and diastolic blood pressure.

Mental stress generally induces sympathetic activation and parasympathetic withdrawal, along with HPA (hypothalamicpituitary adrenal) axis activation. The increased sympathetic nervous activity and decreased parasympathetic nervous activity are considered to be the major outcome in highly stressed subjects $[\mathbf{2 6 , 2 7}$. Subjects who complain more symptoms under stressed conditions may react with acute stress in a different manner from less stressed individuals. The purpose of this study was to clarify the influence of persistent mental stress on mental and physiological state along with response characteristic to the two types of stimuli.

Therefore, the responses of autonomic nervous system and mood to physical and psychological stimuli were examined to clarify the response characteristic in females under persistently high demanding situation, as well as basal mental and physiological states, and compared to those under control situation. Orthostatic challenge and Stroop color-word conflict test (Stroop test) were applied as a physical stimulus and a psychological stimulus, respectively.

\section{Methods \\ Subjects}

The study was approved by The Ethics Committee at our university beforehand. Participants were 21 or 22 years old female college students who were going to have 4 weeks of practice teaching at elementary schools. Eighteen subjects (mean age 21.07 years, range 19-22) participated in the study after providing written informed consents in accordance with the Declaration of Helsinki. Experiment days were planned on Saturday or Sunday after 2 to 3 weeks from the start of teaching practice period, and control experiments were planned 4 weeks later (after 2 to 3 weeks from the end of teaching practice period) to minimize the effects of menstrual cycle on mood and autonomic nervous system. The day of week and time of the day, of the two experiments were matched in each subject, to minimize circadian rhythm effects on mood and autonomic nervous system [29]. They were asked to abstain from eating, and drinking for at least 3 hours before the experiment, and to sleep for more than 6 hours on the previous night. Strenuous exercise, heavy drink and taking medicine on the previous day were also prohibited. Blood pressure data in both periods were not obtained in 4 cases due to mechanical trouble, then, these data were excluded for the analysis.

\section{Study procedures}

The experimental procedure is shown in Figure 1. The subjects entered the room and were asked to fill out CMI and STAI questionnaires. They were also asked to fill out POMS questionnaires and to write down VAS for an evaluation of their basal mood state. Each subject was relaxed in the semi-supine position on a reclining chair while disc electrodes were attached for chest electrocardiograms (ECG) with CM5 leads, and a thermistor was attached just under one nostril for detecting respiration. A tonometric sensor was attached on a radial artery to measure blood pressure (BP) with the tonometric method (JENTOW, Japan). ECG, BP, and respiration curves were recorded during the 10-minute pre-stimulus basal period (5-minute data just

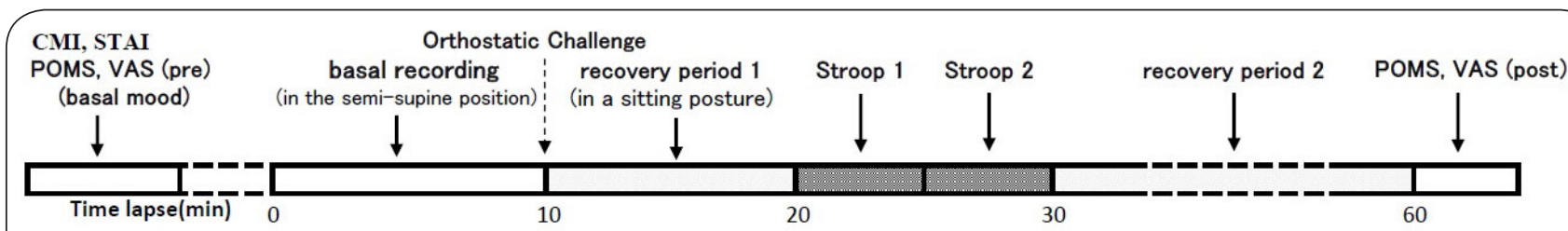

Figure 1. Sequence of experimental procedure.

Recovery period 1 (in a sitting posture), and recovery period 2 were divided into 5 minute epochs named sitting 1, 2 and post 1, 2, 3 , $4,5,6$, respectively, for later analysis. 
prior to orthostatic challenge was used to evaluate basal value), physical stimulus (orthostatic challenge) and recovery period of 10 minute, and psychological stimulus (stroop and reverse stroop test) period of 10 minutes, and 30 minute recovery phase after the 2 nd stimulus, followed by a post-stimulus POMS and VAS period of a few minutes. The stimuli were presented in a fixed order. Data were stored on a personal computer equipped with a 12-bit analog-digital converter (ADTM-98, Canopus, Kobe, Japan) for subsequent offline analysis with a sampling frequency of $1 \mathrm{kHz}$. Each phase was divided into 5-minute epochs and named basal, sitting1, sitting 2, stroop1, stroop2, post1, post2, post3, post 4, post5, post6 for later analysis.

Subjects were asked to keep quiet, avoiding any disruptive movements of their heads or hands throughout the experiments. They were also asked to keep their eyes closed but not to fall asleep, except for stroop test periods. Immediately after recovery period they were asked to fill out POMS questionnaires, and to check VAS for an evaluation of whatever mood states were induced by the 2 nd stimulus.

POMS data were summed to generate six subscales: T-A (tension and anxiety), D (depression and dejection), $\mathrm{A}-\mathrm{H}$ (anger and hostility), V (vigor), F (fatigue), and C (confusion). These summed raw scores were converted into T-scores for parametric statistical analysis according to the POMS manual [21].

Subjects were exposed to orthostatic challenge by setting back the reclining chair from 125 degree to upright position (90 degree) which took usually 10 to 20 seconds. Computerized Stroop and reverse stroop tests (made with SuperLab 4.5, Cedrus corporation, USA) were applied by presenting color name words (blue, green, yellow, and red) in a color which was either congruent or incongruent with the name on a PC display. Subjects were asked to push "color name" button which indicates the color in stroop test, and to push "colored" button which was indicated by color name word in the reverse stroop test. Color name words in a color were presented randomly for 5 minutes in each test. They were instructed to perform the test as accurately and quickly as possible.

\section{Data acquisition and analysis Analysis of psychological indices}

The Cornell Medical Index (CMI) consists of 18 sections and 195 items. The A-L sections (144 items) represent physical state and the M-R sections (51 items) represent mental state. Participants answered "yes" or "no" to indicate the presence or absence of a symptom or disorder. If the answer was "yes," it indicated that the patient had symptoms and received a score of 2. On the other hand, a "no" answer indicated that the patient had no symptoms and was scored at one point [15]. This study used the Japanese version of the CMI, which was created by Kanehisa and Fukamachi (1972) [16]. CMI data were manually scored and summed for physical, mental and C.I.J. symptoms. C (cardiovascular system), I (fatigability), and J (frequency of illness) scores have been found effective to assess neurotic tendencies along with mental symptom scores.

\section{Visual analogue scale (VAS)}

Subjective momentary feelings were evaluated by the VAS which was a horizontal line, $100 \mathrm{~mm}$ in length, anchored by word descriptions at each end, and a participant marks on the line the point that they feel represents their current feeling state [18-20]. Each score was determined by measuring the distance from the left end to the point they marked. The VAS was applied for the assessment of perceived stress level. Higher ratings on each scale indicated more stressed.

\section{HRV analyses}

ECG data were digitized at a sampling frequency of $1 \mathrm{kHz}$ on a personal computer. After detecting every R-wave peak, consecutive R-R intervals on the ECG were calculated, excluding ectopic beats and abrupt discharges in R-R intervals. Spectral analysis was applied to the time series data of R-R intervals for each epoch, using the maximum-entropy method (MemCalc Version 2.5, Suwa Trust) [30]. After calculating the power-spectral density, the magnitude of the power for HRV was obtained by measuring areas under the spectral density curves. The values were divided into two major bands, a low-frequency component (LF; 0.04$0.15 \mathrm{~Hz}$ ) and a high-frequency component (HF; 0.15-0.4 Hz). Thereafter, the amplitude of each frequency band was calculated as twice the power magnitude and the square root thereof. It is known that the HF corresponds to respiratory sinus arrhythmia (RSA) and reflects parasympathetic nerve activity, and the LF corresponds to Mayer-wave-related sinus arrhythmia and relates to both sympathetic and parasympathetic nerve activities [22-25,28]. Then HF amplitude (HF) was considered as an index of parasympathetic nervous function and LF/HF amplitude (LF/HF) as a marker of relative sympathetic activity $[\mathbf{2 4 , 2 9 ]}$.

$\mathrm{BP}$ wave forms were not obtained because of the machine trouble, therefore, BP data were read from the display once at the beginning of the experiment for an evaluation of basal BP. For physiological data analysis, five-minute data just prior to the stimulus period were used to establish pre-stimulus basal activity (basal), and 10-minute data for the recovery phase after orthostatic challenge, and post stimulus rest period were divided into 5-minute epochs and represented as sitting 1,2 and post $1,2,3,4,5,6$, respectively. Responses to the stimuli and recoveries from the stimuli, as well as entire trend, were analyzed separately, since there may be some differences between response and recovery.

\section{Statistical analysis}

To clarify the characteristics of subjective symptoms, mental state and basal BP during teaching practice period, student's paired $t$-test was applied to clarify the difference of basal value in each index during the practice period and control period, along with Spearman's rank correlation coefficient calculation to know the correlations of basal value changes in these indices between both periods. To know the characteristics of mood responses to physical and psychological stimulus during teaching practice period, interactions between period (during teaching practice 
period and during control period) and response of each subscale of POMS and VAS were examined by repeated measures analysis of variance (ANOVA). A repeated measures ANOVA is referred to as a within-subjects ANOVA and is suitable to investigate changes in values over time from the same participants, and can examine the difference of trend of values among groups or those obtained under different situations. To clarify the characteristics of autonomic responses to physical and psychological stimulus during teaching practice period, interactions between period (during teaching practice period and during control period) and entire time course of HF amplitude and LF/HF amplitude were examined by repeated measures ANOVA. Furthermore, to clarify the difference of response characteristic, repeated measures ANOVA were applied to the autonomic responses to, and recoveries from physical and psychological stimulus during both periods. Student's $t$-test was applied to clarify the difference between basal value in each subscale of POMS and perceived stress level (VAS) during the practice period and those during control period. Effect size (Cohen's d for student's $t$-test, and partial $\eta^{2}$ for repeated measures ANOVA) was also calculated to help readers better understand the importance of the findings in this study [31-33]. Statistical analysis was performed on a personal computer using Statview Ver. 5.0 (HULINKS), and differences with a probability value of less than 0.05 were considered significant.

\section{Results}

\section{Basal mental state}

Basal mental state was assessed by CMI and STAI. CMI scores and STAI scores along with BP data obtained during the practice period and those obtained during control period (4 weeks later) were represented in Figure 2. Physical, mental and C.I.J. score of CMI during the practice period were significantly higher than those obtained during control period (physical: $18.278 \pm 2.045$ vs $14.944 \pm 1.969$ (mean \pm SE), $p=0.0008, d=0.403$, mental: $7.500 \pm 1.334$ vs $5.056 \pm 0.944(\operatorname{mean} \pm \mathrm{SE}), p=0.0113$, $\mathrm{d}=0.513$, C.I.J.: $2.889 \pm 0.548$ vs $1.944 \pm 0.514$ (mean \pm SE), $p=0.0396$, $\mathrm{d}=0.431)$. State Anxiety and Trait Anxiety score of STAI dur- ing the practice period were significantly higher than those obtained during control period (state anxiety: $49.222 \pm 2.483$ vs $40.278 \pm 1.627$ (mean $\pm S E), p=0.0051, d=1.033$, trait anxiety: $49.722 \pm 1.715$ vs $39.667 \pm 1.667($ mean $\pm S E), p=0.0005, d=1.442$ ).

\section{Mood response}

Mood was assessed by POMS and VAS, and its responses were examined applying two types of stimulus (physical stimulus: orthostatic challenge, psychological stimulus: stroop tests). Repeated measures ANOVA showed significant period $\times$ mood response interaction in T-A subscale $(\mathrm{F}(1,17)=39.010, p<0.0001$, partial $\left.\eta^{2}=0.696\right)$, D subscale $(\mathrm{F}(1,17)=5.593, p=0.0302$, partial $\left.\eta^{2}=0.248\right)$, F subscale $(\mathrm{F}(1,17)=17.531, p=0.0006$, partial $\left.\eta^{2}=0.508\right)$, C subscale $(\mathrm{F}(1,17)=10.268, p=0.0052$, partial $\left.\eta^{2}=0.377\right)$ of POMS, that is, pre-stimulus basal scores of T-A, $\mathrm{D}, \mathrm{F}$, and $\mathrm{C}$ were higher and decreased more after the stimulus during the practice period, than during control period (Figure 3). Paired $t$-test revealed significantly higher pre-stimulus basal value, during the practice period than during control period, of T-A (63.095 \pm 1.823 vs $47.143 \pm 1.621, p<0.0001, d=2.243)$, $\mathrm{D}(56.687 \pm 1.320$ vs $50.717 \pm 1.971, p=0.012, \mathrm{~d}=0.863), \mathrm{F}$ (60.444 \pm 1.192 vs $49.932 \pm 2.101, p=0.0001, \mathrm{~d}=1.492)$, and $\mathrm{C}$ $(59.320 \pm 1.973$ vs $49.342 \pm 2.289, p<0.0001, d=1.132)($ mean \pm SE). VAS showed significant period $\times$ stress level response interaction $\left(F(1,17)=11.244, p=0.0038\right.$, partial $\left.\eta^{2}=0.398\right)$, that is, prestimulus basal value of perceived stress level was higher and decreased significantly after the stimuli (mean SE: $47.056 \pm 5.468$ vs $31.167 \pm 5.079, p=0.0149, \mathrm{~d}=0.730$ ) during the practice period, while pre-stimulus basal value of the stress level was lower and increased significantly after the stimuli $(17.333 \pm 3.602 \mathrm{vs}$ $25.222 \pm 4.069, p=0.0457, \mathrm{~d}=-0.496)($ mean \pm SE) during control period (Figure 4). Paired $t$-test also revealed significantly higher pre-stimulus basal value of perceived stress level during the practice period compared to that during control period $(47.056 \pm 5.468$ vs $17.333 \pm 3.602, p=0.0002, d=1.557)($ mean $\pm S E)$.

\section{Basal physiological state}

Basal physiological state was evaluated by systolic and diastolic

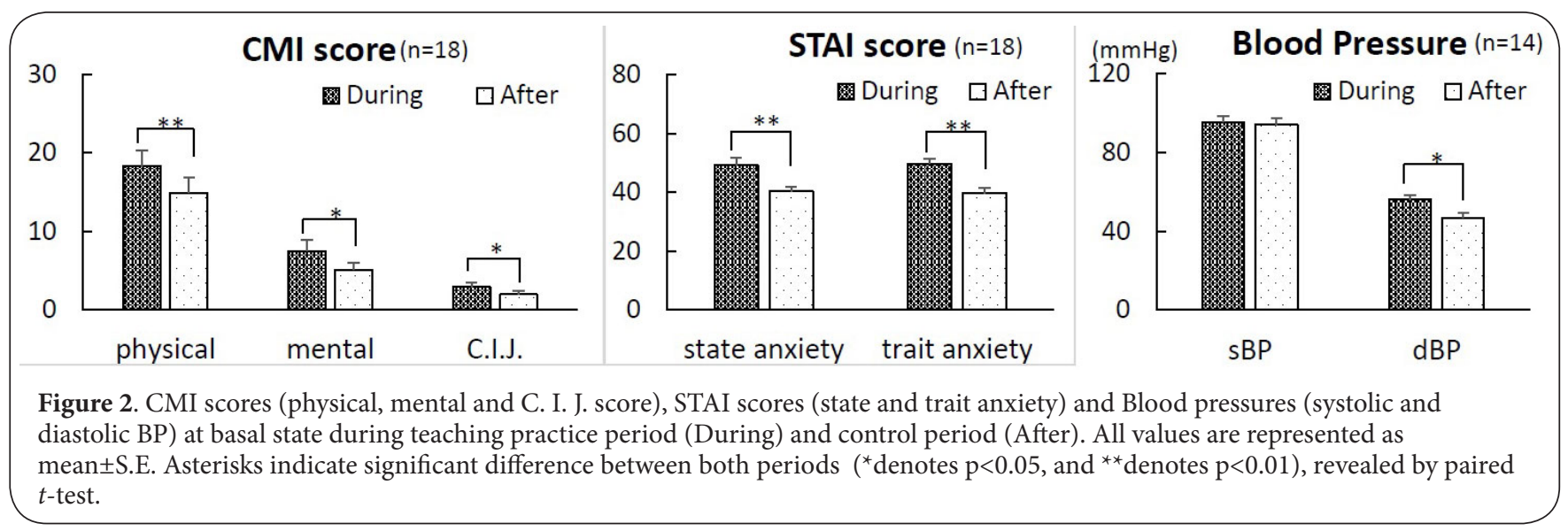



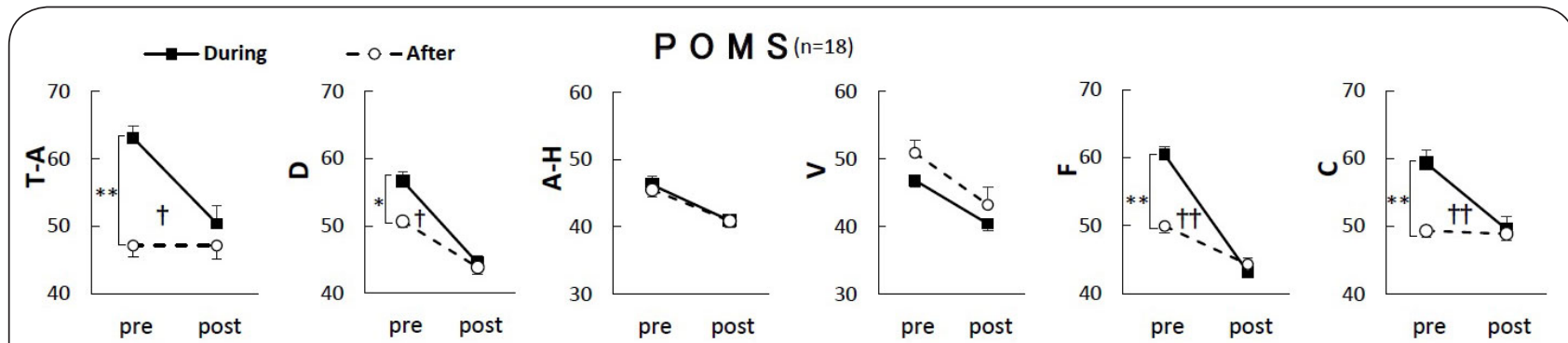

Figure 3. Changes in T-scores of six subscales of POMS in both periods. Closed square: scores during practice period (During), open circle: scores during control period (After). All values are represented as mean $+/-$ S.E. Significant period (during teaching practice period and during control period) $\times$ time course (pre- and post-stimuli) interactions revealed by repeated measures ANOVA were shown in T-A, D, F and C as indicated by daggers ( $\dagger$ denotes $\mathrm{p}<0.05$, and $\dagger \dagger$ denotes $\mathrm{p}<0.01$ ). Asterisks indicate significant difference in pre-stimulus basal values between both periods ( ${ }^{*}$ denotes $\mathrm{p}<0.05$, and ${ }^{* *}$ denotes $\mathrm{p}<0.01$ ), revealed by paired $t$-test. T-A: Tension-Anxiety, D: Depression-Dejection, A-H: Anger-Hostility, V: Vigor, F: Fatigue, C: Confusion.

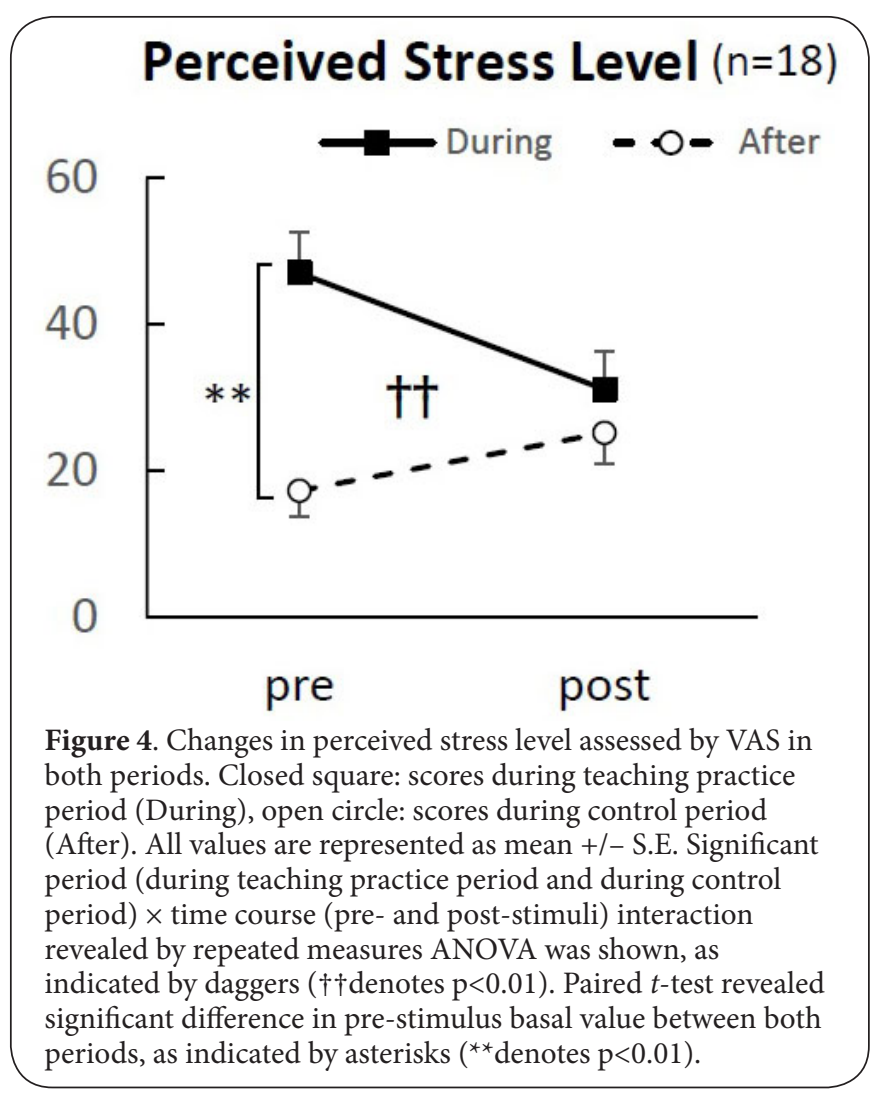

$\mathrm{BP}$, along with pre-stimulus basal value of HF amplitude and LF/HF amplitude. Figure 2 represents systolic and diastolic BP obtained during the practice period and those obtained during control period, in which diastolic BP during the practice period was significantly higher than that during control period (55.929 \pm 2.588 vs $46.857 \pm 2.648$ (mean \pm SE), $p=0.0373, \mathrm{~d}=0.961)$. Paired $t$-test revealed significantly higher LF/HF amplitude $(0.933 \pm 0.0896$ vs $0.744 \pm 0.0745$ (mean \pm SE), $p=0.0257, d=0.555)$ at pre-stimulus basal situation during the practice period, compared to that during control period.

\section{Autonomic nervous response}

Autonomic nervous activity was evaluated by HF amplitude and LF/HF amplitude of HRV, and its responses were examined applying two types of stimulus. There was no significant period $\times$ time course interaction or main effect of period in entire trend of HF amplitude, while mean HF amplitudes within most 5-minute epochs were lower during the practice period, compared to those during control period. No significant period $x$ time course interaction or main effect of period in entire trend of LF/HF amplitude was revealed, while most mean LF/HF amplitudes seemed higher on the whole during the practice period than those during control period. No significant period $\times$ time course interaction or main effect of period was revealed in both HF amplitude and LF/HF amplitude, in responses to the stimuli, or in recoveries from the stimuli (Figure 5). Recovery of HF amplitude after the Stroop Test seems some what less stable and to have decreasing tendency during the practice period compared to that during control period, though the statistic value did not reach the significance $(\mathrm{F}(6,102)=1.916, p=0.0852$, partial $\eta^{2}=0.10129$ ) (Figure 5).

\section{Correlations between changes of the basal values}

Change of physical symptom score (the score during the periodthat during control period) was significantly correlated with change of basal LF/HF amplitude $(\rho=0.475, p<0.05)$. Change of mental symptom score was significantly correlated with change of basal diastolic BP $(\rho=0.600, p<0.05)$. Change of basal systolic $\mathrm{BP}$ was significantly correlated with change of basal diastolic BP $(\rho=0.795, p<0.01)$. Change of state anxiety score of STAI was not significantly correlated with change of trait anxiety score $(\rho=-0.337, p>0.05)$.

\section{Discussion}

Subjective symptoms during the practical teaching practice period were significantly higher than those during control period, and the changes of physical and mental score were significantly correlated with changes of basal LF/HF amplitude and basal 


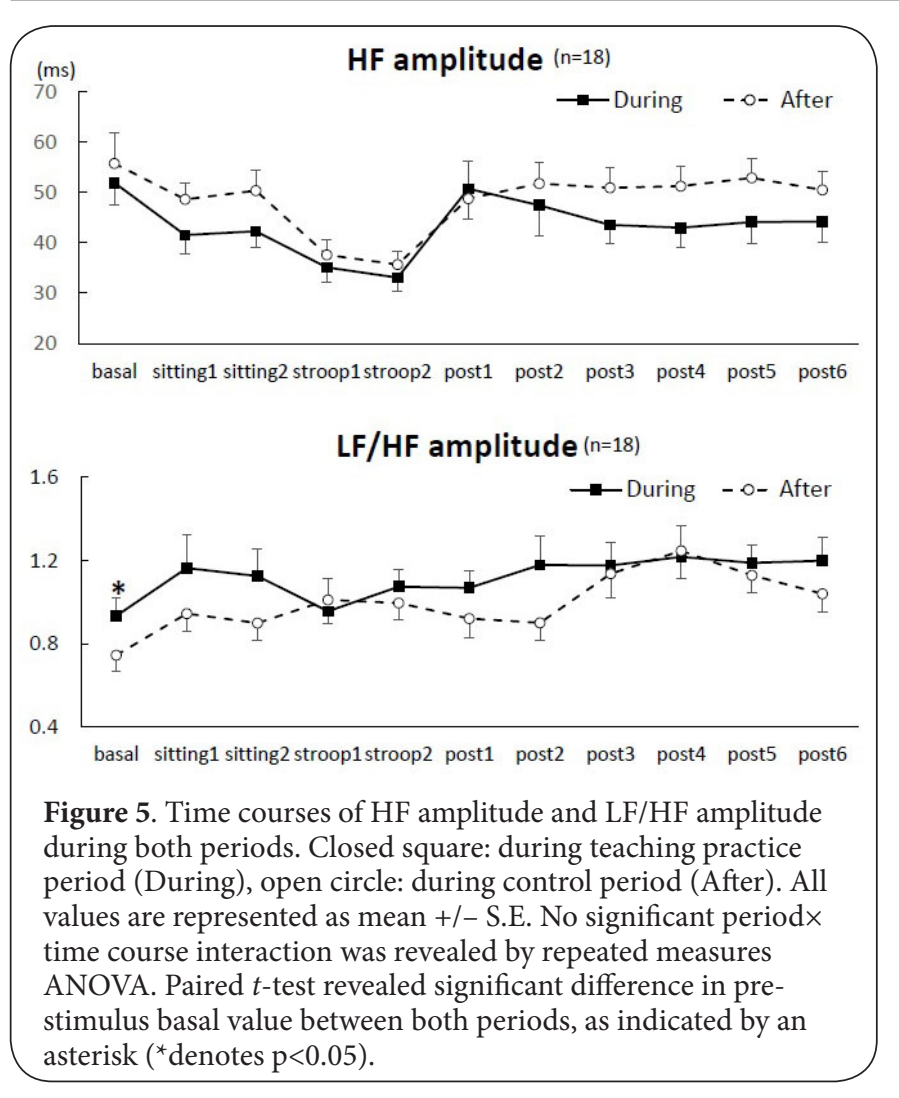

diastolic BP, respectively. Persistent teaching practice would have surely increased subjective symptoms associated with the change of autonomic nervous activity, though the increase would have been transient. State and trait anxiety during the practical practice period were also significantly higher than those during control period. Cohen's $d$ in trait anxiety comparison was the largest among $3 \mathrm{CMI}$ and 2 STAI indices. Cohen's $\mathrm{d}$ is used to indicate standardized difference between two means, and the larger value means stronger effect [31-33]. Trait anxiety is considered to remain fairly consistent during usual life, while state anxiety would represent momentary state of anxiety [17]. Quiñones et al., reported higher levels of trait anxiety in women with endometriosis who would have been persistently under high-stressed state, even though the levels of state anxiety in women with endometriosis were not significantly different from those in healthy controls [34]. Then, I considered trait anxiety as the most important index to detect persistent stress. That is, practical teaching practice would be highly demanding and stressful for female college students, and consequently causes stressed state persistently which would be reflected in relatively high trait anxiety score during practice period.

Negative mood subscales in POMS were higher at basal state during the practical practice period, but reduced after the stimuli as if the participants were released from stress. Stroop test is usually stressful and increases negative mood [35], however, the stimulus seemed to have some relaxation effect during the practice period. When a person is exhausted and chronically stressed with work, a performance of quite different type from the work may work as a distracter, and may have a beneficial effect on mood, though the effect might be temporary.

Basal diastolic BP was significantly higher during the practice period compared to that during control period, though systolic $\mathrm{BP}$ was not significantly different. Blood pressure is regulated precisely by several systems, such as anti-diuretic hormone, arterial baroreflex, renin-angiotensin-aldosterone system, and atrial natriuretic peptide [36]. Influence of persistent stress on systolic blood pressure might be confounded by these regulatory systems or the other factors, and could be observed only in diastolic BP. BP can easily vary according to mental arousal level, physical demand, circadian rhythm, room temperature or the season. Precise diastolic BP monitoring, such as periodically measuring $\mathrm{BP}$ at the same time of a day under the same situation with the same posture on a regular basis, could be helpful to detect persistently stressed state.

Mean HF amplitudes were mostly lower and mean LF/HF amplitudes were mostly higher throughout the experiment during the practice period, however, the entire trends were not significantly different between both periods. The pre-stimulus basal LF/HF amplitude was significantly higher during practice period. Response of HF amplitude to both stimuli were not significantly different, however, recovery from the psychological stimulus during the practice period seemed some what unstable with decreasing tendency. These findings would indicate increased sympathetic activity and decreased parasympathetic activity during the practice period, however, these changes were slight compared to mental state changes. Teixeira et al., reported hyporeactivity of the autonomic nervous system to acute mental stress (Stroop test) in male subjects with chronic psychological stress along with impaired cognitive performance [13]. I reported delayed recovery from acute mental stress in females with gastrointestinal symptoms who would possibly have more or less chronic stress [37]. It is plausible to speculate that unstable or delayed recovery from acute stress would prolong the influence of stress and accumulate to alter basal values, which may possibly result in blunted reactivity to acute stress. The stress level and/or duration in this study would less than the above study, since all the participants in this study were attending university without any problems after the practice period. Some what unstable recovery from the stimuli during the practice period in this study may suggest a tiny malfunction in autonomic nervous system, and may be a sign of initial process in autonomic exhaustion induced by persistent stress.

Change of trait anxiety score of STAI were not significantly correlated with that of basal diastolic BP or the other basal autonomic indices. Psychosocial stressors may influence differently to mental state and to autonomic nervous system, though the change of subjective symptoms had some correlation with autonomic indices. Both mental state and autonomic malfunction may contribute to the subjective symptoms.

The result of the study should be cautiously interpreted, because the sample size was small and the environments of teach- 
ing practice were different from person to person, because each student was assigned to distinct elementary school. Furthermore, we could not determine whether the values during control period surely returned to their basal levels or some influences on the values still remained after the period, since we did not examine any values prior to the practice period.

\section{Conclusions}

More subjective symptoms, more anxiety, higher basal negative mood, and higher basal diastolic BP were found, along with somewhat unstable HF amplitude recovery from the Stroop test during the practice period in female college students. Effect size of trait anxiety difference between both periods was the largest. Therefore, trait anxiety score of STAI, as well as diastolic BP check on a regular basis, can be a useful tool to detect persistently stressed state in females.

\section{Competing interests}

The author declares that he has no competing interests.

\section{Acknowledgement}

The author thanks subjects for their participation to the study. The author is also very grateful to the students, Chiaki Asakura, Yuki Amano, MayukoTaera, RieTasoda, and Misaki Furutate for data collection and analysis in the study.

\section{Publication history}

Editor: Jennifer Piazza, California State University, USA. Received: 25 October 2016 Revised: 05 November 2016 Accepted: 15 November 2016 Published: 18 January 2017

\section{References}

1. Murray CD, Flynn J, Ratcliffe L, Jacyna MR, Kamm MA and Emmanuel AV. Effect of acute physical and psychological stress on gut autonomic innervation in irritable bowel syndrome. Gastroenterology. 2004; 127:1695-703. | Article | PubMed

2. Pieper S, Brosschot JF, van der Leeden R and Thayer JF. Cardiac effects of momentary assessed worry episodes and stressful events. Psychosom Med. 2007; 69:901-9. | Article | PubMed

3. Abdulghani HM, AlKanhal AA, Mahmoud ES, Ponnamperuma GG and Alfaris EA. Stress and its effects on medical students: a cross-sectional study at a college of medicine in Saudi Arabia. J Health Popul Nutr. 2011; 29:516-22. | PubMed Abstract | PubMed FullText

4. Oderhowho A and Tejada-Simon M.V. Periconceptional stress in C57BL/6J female mice leads to altered behavioral responses in their offsprings. Annals of Neuroscience and Psychology. 2015; 2:8.

5. Dishman RK, Nakamura Y, Garcia ME, Thompson RW, Dunn AL and Blair SN. Heart rate variability, trait anxiety, and perceived stress among physically fit men and women. Int J Psychophysiol. 2000; 37:121-33. I Article I PubMed

6. Hamer M and Steptoe A. Association between physical fitness, parasympathetic control, and proinflammatory responses to mental stress. Psychosom Med. 2007; 69:660-6. | Article I PubMed

7. Foley $P$ and Kirschbaum C. Human hypothalamus-pituitary-adrenal axis responses to acute psychosocial stress in laboratory settings. Neurosci Biobehav Rev. 2010; 35:91-6. | Article | PubMed

8. Stern C.M. Corticotropin-Realasing Factor in the Hippocampus: Eustress or Distress. J Neurosci. 2011; 31:1935-6.

9. Aschbacher K, O'Donovan A, Wolkowitz OM, Dhabhar FS, Su Y and Epel E. Good stress, bad stress and oxidative stress: insights from anticipatory cortisol reactivity. Psychoneuroendocrinology. 2013; 38:1698-708. Article | PubMed Abstract | PubMed FullText

10. Hellhammer J and Schubert M. The physiological response to Trier Social Stress Test relates to subjective measures of stress during but not before or after the test. Psychoneuroendocrinology. 2012; 37:119-24. | Article I PubMed

11. Schubert C, Lambertz M, Nelesen RA, Bardwell W, Choi JB and Dimsdale $\mathrm{JE}$. Effects of stress on heart rate complexity--a comparison between short-term and chronic stress. Biol Psychol. 2009; 80:325-32. | Article | PubMed Abstract | PubMed FullText

12. Borchini R, Bertu L, Ferrario MM, Veronesi G, Bonzini M, Dorso M and Cesana G. Prolonged job strain reduces time-domain heart rate variability on both working and resting days among cardiovascularsusceptible nurses. Int J Occup Med Environ Health. 2015; 28:42-51. | Article I PubMed

13. Teixeira RR, Diaz MM, Santos TV, Bernardes JT, Peixoto LG, Bocanegra $\mathrm{OL}$, Neto MB and Espindola FS. Chronic stress induces a hyporeactivity of the autonomic nervous system in response to acute mental stressor and impairs cognitive performance in business executives. PLOS One. 2015; 10:e0119025. | Article | PubMed Abstract | PubMed FullText

14. Jonsson P, Osterberg K, Wallergard M, Hansen AM, Garde AH, Johansson $\mathrm{G}$ and Karlson B. Exhaustion-related changes in cardiovascular and cortisol reactivity to acute psychosocial stress. Physiol Behav. 2015; 151:327-37. | Article | PubMed

15. Costa PT, Jr. and McCrae RR. Psychiatric symptom dimensions in the Cornell Medical Index among normal adult males. J Clin Psychol. 1977; 33:941-6. | PubMed

16. Kanehisa T, Fukamachi K and Nozoe S. Japanese-version Cornell Medical Index health questionnaire (in Japanese). Kyoto, Sankyobo. 2011.

17. Spielberger C.D, Gorsuch R.L and Lushene R.E. The State-Trait Anxiety Inventory: Test Manual. Palo Alto, CA: Consulting Psychologist Press. 1970.

18. McCormack H.M, Horne D.J and Sheather S. Clinical application of visual analogue scales: a critical review. Psychological Medicine. 1988; 18:1007-19.

19. Wewers ME and Lowe NK. A critical review of visual analogue scales in the measurement of clinical phenomena. Res Nurs Health. 1990; 13:227-36. | PubMed

20. Gould D, Kelly D, Goldstone L and Gammon J. Examining the validity of pressure ulcer risk assessment scales: developing and using illustrated patient simulations to collect the data. J Clin Nurs. 2001; 10:697-706. I Article I PubMed

21. Yokoyama K and Araki S. POMS Japanese manual (in Japanese). Kaneko Syobo, Tokyo, Japan. 1994.

22. Akselrod S, Gordon D, Madwed JB, Snidman NC, Shannon DC and Cohen RJ. Hemodynamic regulation: investigation by spectral analysis. Am J Physiol. 1985; 249:H867-75. I Article I PubMed

23. Pomeranz B, Macaulay RJ, Caudill MA, Kutz I, Adam D, Gordon D, Kilborn KM, Barger AC, Shannon DC, Cohen RJ and et al. Assessment of autonomic function in humans by heart rate spectral analysis. $\mathrm{Am} \mathrm{J}$ Physiol. 1985; 248:H151-3. I Article I PubMed

24. Pagani, M., Lombardi, F., Guzzetti, S., Rimoldi, O., Furlen, R., Pizzinelli, P., Sandrone, G., Malfatto, G., Dell'Orto, S., Piccaluga E, Turiel M, Baselli $G$, Cerutti $S$ and Malliani A. Power spectral analysis of heart rate and arterial pressure variabilities as a marker of sympathovagal interaction in man and conscious dog. Circ Res. 1986; 59:178-92.

25. Berger R.D, Saul J.P and Cohen R.J. Transfer function analysis of autonomic regulation. I. Canine atrial rate response. Am J Physiol. 1989; 256:H142-52.

26. Langewitz W, Ruddel H, Schachinger H, Lepper W, Mulder LJ, Veldman JH and van Roon A. Changes in sympathetic and parasympathetic cardiac activation during mental load: an assessment by spectral analysis of heart rate variability. Homeost Health Dis. 1991; 33:23-33. I PubMed

27. Pagani M, Rimoldi O, Pizzinelli P, Furlan R, Crivellaro W, Liberati D, Cerutti $\mathrm{S}$ and Malliani A. Assessment of the neural control of the circulation during psychological stress. J Auton Nerv Syst. 1991; 35:33-41. I Article I PubMed 
28. Montano N, Ruscone TG, Porta A, Lombardi F, Pagani M and Malliani A. Power spectrum analysis of heart rate variability to assess the changes in sympathovagal balance during graded orthostatic tilt. Circulation. 1994; 90:1826-31. | PubMed

29. Malliani A, Pagani M, Lombardi F and Cerutti S. Cardiovascular neural regulation explored in the frequency domain:Research Advances Series. Circulation. 1991; 84:482-92.

30. Ohtomo N, Terachi S, Tanaka Y, Tokiwano K and Kaneko N. New method of time series analysis and its application to Wolf's sunspot number data. Jpn J Appl Phys. 1994; 33:2821-31.

31. Cohen J. Statistical power analysis for the behavioral sciences (2nd ed.). Hillsdale, NJ: Erlbaum. 1988.

32. Faul F, Erdfelder E, Lang AG and Buchner A. G*Power 3: a flexible statistical power analysis program for the social, behavioral, and biomedical sciences. Behav Res Methods. 2007; 39:175-91. | PubMed

33. Mizumoto $A$ and Takeuchi $O$. Basics and considerations for reporting effect sizes in research papers. English Education Research (in Japanese). 2008; 31:57-66.

34. Quinones M, Urrutia R, Torres-Reveron A, Vincent K and Flores I. Anxiety, coping skills and hypothalamus-pituitary-adrenal (HPA) axis in patients with endometriosis. J Reprod Biol Health. 2015; 3. | Article | PubMed Abstract | PubMed FullText

35. Minakuchi E, Ohnishi E, Ohnishi J, Sakamoto S, Hori M, Motomura M, Hoshino J, Murakami K and Kawaguchi T. Evaluation of mental stress by physiological indices derived from finger plethysmography. J Physiol Anthropol. 2013; 32:17. | Article | PubMed Abstract | PubMed FullText

36. Ganong W.F and Okada Y. Japanese version of Ganong's Review of Medical Physiology 21st Edition (in Japanese). Maruzen, Tokyo, Japan. 2004.

37. Sakuragi S. Delayed parasympathetic recovery from a psychological stimulus in female college students with gastrointestinal symptoms. Annals of Neuroscience and Psychology. 2015; 2:3.

\section{Citation:}

Sokichi S. Influences of persistent psychosocial stress in the real world on mental and physiological states in female college students. J Psychiatry Brain Funct. 2017; 3:1. http://dx.doi.org/10.7243/2055-3447-3-1 